Bekkema, N., Veer, A.J.E. de, Hertogh, C.M.P.M., Francke, A.L. Respecting autonomy in the ench of-life care of people with intellectual disabilities: a qualitative multiple-case study. Journal of Intellectual Disability Research: 2014, 58(4), 368-380

\begin{tabular}{|l|l|}
\hline $\begin{array}{l}\text { Postprint } \\
\text { Version }\end{array}$ & 1.0 \\
\hline Journal website & $\underline{\text { http://onlinelibrary.wiley.com/doi/10.1111/jir.12023/abstract }}$ \\
\hline Pubmed link & $\underline{\text { http://www.ncbi.nlm.nih.gov/pubmed/23510011 }}$ \\
\hline DOI & $10.1111 /$ jir.12023 \\
\hline
\end{tabular}

This is a NIVEL certified Post Print, more info at http://www.nivel.eu

\title{
Respecting autonomy in the end-of-life care of people with intellectual disabilities: a qualitative multiple-case study
}

\author{
N. BeKKema ${ }^{1, *}$, A. J. E. DE VeER ${ }^{1}$, C. M. P. M. HertoGH ${ }^{2}$, A. L. FrANCKE ${ }^{1,2}$ \\ ${ }^{1}$ NIVEL - Netherlands Institute for Health Services Research, Utrecht, the Netherlands \\ ${ }^{2}$ EMGO Institute for Health and Care Research, VU University Medical Centre, Amsterdam, \\ the Netherlands
}

\begin{abstract}
Background: The aim of this article was to describe how caregivers and relatives shape respect for autonomy in the end-of-life care for people with intellectual disabilities (ID) and to discuss to what extent this corresponds with a relational concept of autonomy, such as described in care ethics.

Method: This study consisted of a qualitative design in which the cases of 12 recently deceased people with ID were reconstructed by interviewing the caregivers and relatives who were closest to the person at the end of their life. A cyclic process of data collection and analysis was used. Interviews were transcribed verbatim and data were analysed inductively.

Results: Respect for autonomy in the end-of-life care of people with ID was mainly reflected in helping the person with ID familiarise with three transitions: new information on the diagnosis and prognosis, changing care needs and wishes, and important decisions that were at stake. In respecting autonomy, relatives and caregivers encountered several challenges. These concerned ascertaining information needs, communicating about illness and death, inexperience in end-of-life care, eliciting current and hidden last wishes, the dependence of people with ID and conflicting wishes. Several qualities were important for respecting autonomy: attention to information needs, connecting, recognising end-of-life care needs, giving space to show wishes and preferences, and discussing dilemmas.

Conclusions: If caregivers and professionals embrace autonomy as a relational construct, attained through an open, active and reflective attitude, and have more access to knowledge about communication and how to identify end-of-life care needs, this could lead to improved respect for the ID persons' autonomy at the
\end{abstract}


Bekkema, N., Veer, A.J.E. de, Hertogh, C.M.P.M., Francke, A.L. Respecting autonomy in the ench of-life care of people with intellectual disabilities: a qualitative multiple-case study. Journal of Intellectual Disability Research: 2014, 58(4), 368-380

end of life. We discuss the view that a relational concept of autonomy is useful for describing respect for autonomy in end-of-life care for people with ID, but that more reflection and openness is needed to sufficiently employ relationships and regard autonomy as a product of joint work.

\section{INTRODUCTION}

As an important value in healthcare, respect for autonomy is also embedded in the care for people with intellectual disabilities (ID). The American Association on Intellectual and Developmental Disabilities (AAIDD) views autonomy as a major principle in disability policy and states that caregivers should always try to discover what the person with intellectual or developmental disabilities wants (as much as possible) and honour those wishes (see the position statement on 'Caring at the End of Life' issued in 2005). In general, respecting autonomy at the end of life can be particularly strenuous as most people become increasingly dependent on others (Proot et al. 2004; Winzelberg et al. 2005; Claessen et al. 2011). Several autonomyrelated challenges may arise, such as unwanted dependence, losing control and limitations to activities (Proot et al. 2004; Vernooij-Dassen et al. 2005). The majority of people with ID have already been heavily dependent on others in previous phases of their life. Respecting autonomy at the end of life may be an especially challenging issue in this target group as people with ID become even more dependent in the last phase of their life because of existing cognitive impairments combined with physical impairments resulting from a life-limiting illness. Their wishes and needs at the end of life may therefore not be self-evident.

In modern ethics, respect for patient autonomy is approached in many different ways. Patient autonomy is often described in 'liberal' terms where people know what is best for themselves. In the well-known 'Principles of Biomedical Ethics', for example, the ethicists Beauchamp \& Childress (2001) define autonomy in terms of being able to choose and think for oneself, based on a notion of the 'independent and free self' as the highest ideal. Respecting autonomy here means that people must be given the opportunity to decide for themselves without interference from others. One could question, however, whether a liberal notion of autonomy adequately suits the context of end-of-life care, as many people are strongly reliant on others then, and even more, whether it would suit the end-of-life care of highly dependent people, such as people with ID.

A notion of autonomy that gives more space to the dependence of people may be found in care ethics, which represents a more relational conception of autonomy. For example, in her book Moral Boundaries, Tronto (1993, p. 162) states:

... humans are not fully autonomous, but must always be understood in a condition of interdependence. While not all people need others' assistance at all times, it is a part of the human condition that our autonomy occurs only after a long period of dependence, and that in many regards, we remain dependent on others throughout our lives.

Tronto emphasises that we humans are never independent of others and that we will always need others to 'reach' a notion of autonomy. Other authors have elaborated on this relational concept of autonomy. Verkerk, for example, argues that autonomy cannot be seen in isolation from other people and relationships, that both caregiver and care receiver have responsibilities in maintaining the relationship, and by 
Bekkema, N., Veer, A.J.E. de, Hertogh, C.M.P.M., Francke, A.L. Respecting autonomy in the ench of-life care of people with intellectual disabilities: a qualitative multiple-case study. Journal of Intellectual Disability Research: 2014, 58(4), 368-380

maintaining that relationship, they guard the autonomy of the patient (Verkerk 1999, 2001). A relational notion of autonomy can also be found in Agich's concept of actual autonomy. Agich defines autonomy as the ability to identify with changing circumstances and he views dependence as an essential feature of human development (Agich 2003). A relational concept of autonomy has been incorporated in empirical studies of people with ID, for example on overeating behaviour in Prader-Willi syndrome (Van Hooren et al. 2002). The relational concept of autonomy has also been incorporated in the ethical reflections of Verkerk \& Maeckelberghe (2003), who argue that respecting the autonomy of people with ID requires responsible, attentive caregivers who are able to listen and empathise with the view of the world taken by people with ID, and who constantly reflect on their work. According to this vision, autonomy is an achievement rather than an assumption, and is therefore not easily accomplished (Maeckelberghe 2003; Verkerk \& Maeckelberghe 2003).

As medical care has improved over recent decades, the life expectancy of people with ID is approaching that of the general population and causes of death are comparable as well (Janicki et al. 1999; Ellison \& Rosielle 2008). More and more attention is given to the quality of end-of-life care for people with ID (McCallion et al. 2012). Although autonomy is seen as an important value, it has rarely been a subject in relation to healthcare for this group (Wullink et al. 2009) and we found no studies that specifically address respect for the autonomy of people with ID in relation to end-of-life care. Yet there have been studies that indirectly address elements of respect for autonomy, such as truth-telling, the involvement of people with ID in decision-making and life preferences. These studies show that people with ID are often not (fully) informed and involved in decision-making (Friedman 1998; Tuffrey-Wijne et al. 2005, 2006, 2009, 2010; Watchman 2005; Ryan \& McQuillan 2006; Wagemans et al. 2010). People with severe ID in particular were often protected from the truth and not helped to understand the consequences of their diagnosis. Withholding the truth may severely obstruct end-of-life care for people with ID (Tuffrey-Wijne \& McEnhill 2008). Stein \& Kerwin (2010) emphasise that the values and life preferences of people with ID must be well documented, in order to prevent these values from staying unnoticed when end-of-life decisions are at stake.

Although the significance of respecting autonomy in end-of-life care is not disputed, the way in which this is achieved for people with ID remains unclear. This article describes how caregivers and relatives shape respect for autonomy in the end-of-life care for people with ID. We do this by exploring the challenges caregivers and relatives face and the qualities they consider as important for respecting autonomy. In the discussion, we will reflect on the extent to which the results correspond with a relational concept of autonomy as described in care ethics.

\section{METHODS}

\section{Design}

This study consisted of a qualitative design in which the cases of 12 recently deceased people with ID were reconstructed from different perspectives. We held semi-structured interviews with several caregivers and relatives who were close to the person at the end of life. Such a qualitative design is particularly well suited to 
Bekkema, N., Veer, A.J.E. de, Hertogh, C.M.P.M., Francke, A.L. Respecting autonomy in the ench of-life care of people with intellectual disabilities: a qualitative multiple-case study. Journal of Intellectual Disability Research: 2014, 58(4), 368-380

comprehending complex issues such as respect for autonomy, and for grasping the concepts that underlie respect for autonomy in the last phase of life.

\section{Participants}

The interviewees were recruited through contacts with 10 ID care provider organisations in different parts of the Netherlands. Caregivers and relatives of recently deceased people with ID were identified by the contacts, who then asked them whether they would be willing to participate in the study and whether they gave permission to have their names and addresses passed on to the researcher. In total, 47 people (see Table 1) who were close to one of the 12 recently deceased people with ID were interviewed. We included the perspectives of several professional caregivers and trained volunteers as well as relatives (Table 1). In all 12 cases, one or more social workers or nurses were interviewed. In all but one case, at least one relative was interviewed. In nine cases we interviewed physicians: three general practitioners and six physicians specialised in people with ID (ID physicians).

\section{[TABLE 1]}

All interviews concerned the experiences with the care for one of 12 recently deceased people. Relatively diverse cases were selected to take into account the variety of possible end-of-life care circumstances. All 12 people with ID received care from a Dutch ID care provider. All but one person died less than a year before the interview was held, allowing us to retrieve the participants' recent memories. One person died 2.5 years before the time of the interview and was included because of his specific situation, living in a hospice with the assistance of a volunteer. Table 1 shows that the cases comprised six men and six women with different levels of severity of ID. Half of them died of cancer. They reached a mean age of 53 years. Half of them died in their own home, two in an intensive care unit of their ID care provider, three in a hospital and one in a hospice. We asked participants when they realised the death of the person was imminent; this ranged from 2 days to 6 months before the death.

\section{Data collection}

Individual in-depth semi-structured interviews were held at the place of preference of the interviewees. Interviews were conducted between December 2010 and April 2011 by the first author and lasted 1-2 h. Open questions were used, encouraging interviewees to describe the case in their own words. A topic list was used as a guide for formulating interview questions. Topics included communication, the care provided, the living situation and end-of-life decisions. Data collection was part of a cyclic process of data collection and analysis. This cyclic process was repeated until data saturation was reached.

\section{Ethical consideration}

All interviews were treated confidentially and anonymously. As we only held interviews with care professionals and relatives, no formal medical-ethical approval was required according to Dutch law. 
Bekkema, N., Veer, A.J.E. de, Hertogh, C.M.P.M., Francke, A.L. Respecting autonomy in the ench of-life care of people with intellectual disabilities: a qualitative multiple-case study. Journal of Intellectual Disability Research: 2014, 58(4), 368-380

\section{Analysis}

Interviews were taped and transcribed verbatim. Data were analysed inductively, in the sense that the content of the transcribed interviews was given priority in identifying key themes. For the analysis we used descriptive codes, often directly based on words that the interviewees used, and interpretative codes (labels of text fragments that function as concepts). Interview fragments with the same codes were constantly compared during the analysis. Written memos were made concerning the interpretation of codes and the relationships between codes throughout the analysis process. All authors were involved in the entire process from the analyses of interviews to the generation of concepts. All interviews were analysed by the first author. In addition, each co-author individually analysed all the interviews for at least one case. Differences in analysis and interpretations were discussed, for example concerning whether or not relatives and caregivers shared views on end-oflife care with the person with ID or concerning possible interpretations of a situation in which information was withheld from a person with ID. Because the co-authors analysed the interviews in consecutive order, we were able to jointly refine the coding system over time. The correspondence between interpretations and the original interviews was continuously verified using constant comparative analysis. After the first author had discussed a quarter of the interviews with the co-authors, consensus was reached about the interpretation of the codes addressing respect for autonomy. The first author manually checked the interpretations with the existing interviews and then analysed all interviews with MAXQDA 2007 to facilitate coding (http://www.MAXQDA.com). To validate the results, we discussed the findings in two focus groups with ID caregivers, trainers and policy experts (peer debriefing).

\section{RESULTS}

The way respect for autonomy was shaped became especially eminent during three kinds of transitions at the end of life: (1) when new information became available about the diagnosis, prognosis or treatment of the person with ID; (2) when the care needs and wishes of the person with ID changed in the last phase of life; and (3) when important decisions needed to be made, for example about whether or not to begin treatment. In the perception of relatives and caregivers, respect for autonomy mainly concerned the question of how to help the person with ID feel familiar with these transitions.

Figure 1 summarises the challenges that caregivers and relatives met in respecting autonomy during these transitions as well as the qualities they regarded as important for respecting autonomy. These challenges and qualities are explained in more detail below. To illustrate the results we use the cases of Joe, Sabine, Cassandra and Charles because autonomy played an important role in their last phase in life (Table 2). We also discuss the extent to which they resemble the other cases studied.

[FIGURE 1 AND TABLE 2]

\section{Challenges in respecting autonomy}


Bekkema, N., Veer, A.J.E. de, Hertogh, C.M.P.M., Francke, A.L. Respecting autonomy in the ench of-life care of people with intellectual disabilities: a qualitative multiple-case study. Journal of Intellectual Disability Research: 2014, 58(4), 368-380

\section{Ascertaining information needs}

It was usually relatives and caregivers, not the person with ID, who first heard about the prognosis. For relatives and caregivers, this raised the difficult question of how to communicate to the person with ID about the situation, estimate what he/she would want to know and how much information he/she was able to handle. The interviewees thought that the person with ID had the right to be informed. However, in the case of very ill people with severe ID in particular, what they understood about the situation was largely unknown, making it very difficult to ascertain their need for information. In these situations, communication mainly started in the here and now, for example by explaining what kind of examination the doctor wanted to perform. With some people with severe ID no communication took place at all, according to their relatives and caregivers: communication was regarded as impossible because of the low cognitive level.

\section{Communicating about illness and death}

There was more potential for involving people with mild ID in communication about the illness; however, this did not automatically lead to more communication:

Cassandra was informed about her illness and the approaching end of life by her brother only shortly before she died. The social worker of the farm where Cassandra used to work thought, however, that the illness should have been discussed at a far earlier stage in her disease: 'I think that Cassandra would have understood it. Now Cassandra was confused; she felt that something was wrong, everybody behaved strangely, but she did not understand what was going on. It was also confusing for the other workers at the farm, who had to guess why Cassandra was suffering.' The social worker did not regard it as her task to communicate to Cassandra about her illness since she was not her primary caregiver. Moreover, she would not have known how to start communication on such a difficult subject. After Cassandra had passed away, the social worker was still bothered by this.

The social worker observed a need for information in Cassandra, but she did not act upon it. Uncertainty about how to handle difficult subjects combined with the fear of upsetting the person with ID was seen in many cases, especially among social workers, nurses and relatives.

\section{Inexperienced in end-of-life care}

Caregivers and relatives considered it their task to make the person with ID feel as comfortable as possible in the last phase of life. This made them primarily focus on finding out what needs the person had and how to respond to these. The physical care needs of the people with ID changed dramatically in all the cases studied. They encountered more physical problems, were bedridden and needed more help with their daily care. It was especially difficult for social workers to respond adequately, as they lacked nursing skills and basic knowledge of end-of-life care. For some it was the first time they had a client who was dying. Moreover, social workers and nurses had to take over tasks from the person with ID, which tended to conflict with their feelings of respecting autonomy, as they were used to encouraging their clients' independence.

\section{Current and hidden last wishes}


Bekkema, N., Veer, A.J.E. de, Hertogh, C.M.P.M., Francke, A.L. Respecting autonomy in the ench of-life care of people with intellectual disabilities: a qualitative multiple-case study. Journal of Intellectual Disability Research: 2014, 58(4), 368-380

People with mild ID were, more or less, able to communicate their last wishes, like the place of the funeral and the colour of the coffin. However, there remained a need to find out whether these wishes were still applicable:

Charles and his caregivers had previously filled out a book of last wishes regarding the farewell process and the funeral. When he became ill he indicated that he was not happy with his book of wishes: he felt it had been mostly filled in by others.

Together with his social worker, Charles filled out the book of wishes again. 'Charles decided what was going to happen ... Because he was very ill, we could not finish the book in one go, we had to do it in steps. ... Every time he said "let's work on the book”, we worked right through the whole book all over again.' When the book of wishes was finished it turned out to be exactly the same as the previous version. 'It was exactly the same, but he wanted to do it his way.' Charles died the evening the book of wishes was finished.

In contrast to Charles, the wishes of people with severe ID were less clear: they were often hidden. Their wishes were often discussed without involving the person with ID, because of communication difficulties and a lack of discussion of wishes in a healthier stage in life.

\section{Magnified dependence}

Important decisions at the end of life, such as whether or not to start life-prolonging treatment or whether to move to another home, were often taken in multidisciplinary meetings together with relatives. There was no sign from the interviews that the person with ID was present at these meetings. Decisions were based on what were thought to be the wishes of the person with ID or what seemed to be best for that person. In some cases where communication was possible, the wishes of the person with ID were discussed with him or her before the multidisciplinary meeting, but in other cases the person was only informed afterwards, for example about the use of a probe tube or why it was better to move to another home. For people with severe ID, medical decisions were taken by a physician together with relatives. Many relatives found it very hard to take such decisions for a person with ID; as the case of Joe illustrates:

A decision was needed on whether or not to start chemotherapy to lengthen Joe's life. Because of his low cognitive ability, Joe was not able to take this decision for himself. Deciding for Joe was a real burden for his relatives. Joe's illness led to a reflection about their interaction patterns with Joe. His sister came to realize that she had always taken a lot of Joe's preferences for granted, as it turned out that Joe was able to do things she would have never imagined. For example, Joe did not mind so much being in the hospital anymore, and food had become less important to him. She found this hard to accept. 'Joe adapted his desires without us noticing it. It is so frustrating when you have to take decisions for someone else and you find out that you have been wrong about his wishes several times. Joe being intellectually disabled has never been a problem to me, but when he became ill I hated it. I really wanted to talk to him at the same level for just one day - that he could tell me what he wanted and how he felt.' Especially in his last phase in life, Joe's sister became very aware of Joe's dependence. The decisions about prolonging life and about death magnified Joe's dependence: his relatives started to wonder what they had already filled in for Joe earlier in his life. 
Bekkema, N., Veer, A.J.E. de, Hertogh, C.M.P.M., Francke, A.L. Respecting autonomy in the ench of-life care of people with intellectual disabilities: a qualitative multiple-case study. Journal of Intellectual Disability Research: 2014, 58(4), 368-380

\section{Conflicting wishes}

People with mild ID were better able to express their wishes. Although this made communication easier, their wishes could conflict with the wishes of others:

All her life, Sabine had had an aversion to hospitals and doctors. She persisted in her desire for independence and did not want to go to the hospital. She suffered severely from fears and restlessness. Her relatives and caregivers offered her medicines to reduce her fears. But Sabine did not want these; she wanted to decide for herself what was good for her. She was afraid that her caregivers would administer the medication secretly, which is not farfetched as this option had been discussed by her relatives and caregivers. In the end, the choice was given to Sabine herself. It was explained to her clearly what the medicines were for; however, she left the medicines on her bedside table untouched until she died. Her caregivers found it difficult to accept her refusal. Social worker: 'You have to let go and accept that Sabine has her own say. ... But it is always difficult to determine whether she is capable of making these decisions or whether it is better to interfere ... It is hard that you cannot see what she truly understands.' Physician: 'You have the feeling that Sabine does not realize the consequences of not taking the pills.'

Sabine's case shows the struggle her relatives and caregivers had with the dilemma between respect for her own wishes and the moral obligation to provide good care and therefore intervene to reduce her fear symptoms. Respecting Sabine's own wishes probably resulted in her keeping her fears. Because of her ID, there were doubts about her decision-making capacity and judgement. Her caregivers wondered if they did enough to help Sabine understand her situation and if they had sufficiently respected her autonomy. Sabine herself seemed very aware of her dependence, as she was afraid the medicines were administered secretly. Similarly, in Charles's case, his wishes were compromised:

Charles's wish was to die in his own apartment, which was very dear to him. However, his social workers felt that he had the right to receive good, continuous care, including at night, and they felt they were unable to provide this in his apartment. Charles was moved to an intensive care unit. He missed his own apartment a lot. Charles's new nurse thought that his social workers were just too afraid to care for someone with a tumour and possible bleedings. Charles was depressed due to the transition. Charles's new nurse helped Charles understand why he could not go back and tried to make the new situation as comfortable as possible. They took pictures of his apartment and hung them up in his new room. Charles talked proudly about his apartment. After he died, his body was brought back to his apartment and laid out there.

Charles's wish to stay in his apartment led to a dilemma between respecting Charles's wish and the desire to provide high-quality care around the clock. Ultimately, Charles's wish was not answered and he had to accept the new situation. He was helped to accept this transition by his new nurse, who tried to make him feel at home.

\section{Important qualities in respecting autonomy}

The people with ID in the cases studied needed the help of others to meet their wishes and needs and feel familiar with new situations. According to relatives and caregivers, the following qualities were important in respecting autonomy.

Attention to information needs 
Bekkema, N., Veer, A.J.E. de, Hertogh, C.M.P.M., Francke, A.L. Respecting autonomy in the ench of-life care of people with intellectual disabilities: a qualitative multiple-case study. Journal of Intellectual Disability Research: 2014, 58(4), 368-380

Although the interviewees endorsed the ID people's right to be informed, they did not think that all information should be shared; that depended on their estimation of the individual ID person's information needs. Relatives and caregivers were better able to consider information needs if they knew the person well: knew how much that person already understood about the illness and what their attitude towards illness and death had been in the past. This helped carers recognise the signals implying requests for more information or requests to be left alone.

\section{Connecting}

Communication was not only about sharing information but was also a means to help the person feel familiar with his illness. Not everyone had access to these skills, according to the interviewees. An important quality was the ability to connect with the person with ID in such a way that it enabled the person with ID to be accessible to the help offered. Joe's case is one such example:

Joe's sister: 'We talked to him, not really with him, because he was unable to ask questions. Joe could sort of "talk" by pointing. He also pointed at the stars. Perhaps he only meant: "where is daddy now?” Or "the stars are beautiful”, but we interpreted it as: yes that is where daddy is now, daddy is dead. We did not say that daddy is asleep or anything like that. No, we said "daddy is gone and Joe gave his teddy bear to daddy when he died". I thought Joe had the right to know what was going on ... In the end I said to him: "Just as you can show us the direction where you want to walk, you can also tell us the way you want to die. It's your call. Joe is a big boy and Joe can say for himself how he wants to die. It is okay, you may go.” You don't know whether he understands it, but you hope that you are able to communicate a feeling of safety, subconsciously, that it is all right and that there is nothing to be afraid of.'

Joe's sister connected with him by making a link to Joe's previous experiences and by connecting to Joe's way of communicating: pointing. Although Joe's sister did not need any assistance in connecting with her brother, several other interviewees had a need for tools, such as pictures, to facilitate connecting and communication.

\section{Recognising end-of-life care needs}

Caregivers strived to respect autonomy by making the people with ID feel as comfortable and familiar with the situation as possible. They therefore wanted to act on their care needs in the best possible way. This required basic knowledge and skills in end-of-life care that enabled caregivers to recognise a care need, to interpret symptoms like pain, restlessness and fatigue, and to know what type of care should be offered.

\section{Giving space to show wishes and preferences}

Although tracing the preferences of people with a severe ID was very difficult, it was not always impossible:

Joe's sister: 'Actually, we never talked to Joe, but in the last period of his life he expressed himself a lot, just because we gave him the space he needed ... we thought we knew it all, how he was and how he would react. But in fact, this was only half true and he was very well able to show that he was capable of more than we always assumed.' Joe's sister learned from this experience: 'I think that as a caregiver of a relative, you have to look further. Do not assume that the person who you have 
Bekkema, N., Veer, A.J.E. de, Hertogh, C.M.P.M., Francke, A.L. Respecting autonomy in the ench of-life care of people with intellectual disabilities: a qualitative multiple-case study. Journal of Intellectual Disability Research: 2014, 58(4), 368-380

known all his life, will also die in the same way. People can change in that last period and are able to adapt their preferences. You will be surprised. You will restrict yourself if you don't look beyond the person and try things out.'

Although Joe had severe ID, he communicated a lot with his sister in his last stage in life. The sister noticed a change in Joe's preferences at the end of his life. She learned to keep an eye open for the needs of people with ID, as needs can change at the end of life. Joe's sister tried out new moves and activities, and closely observed Joe's reaction to actions, which enabled her to notice, for example, that Joe did not mind so much going to the hospital anymore.

\section{Discussing dilemmas}

In some cases, the wishes of people with ID came into conflict with the wishes and options of others. Sabine's and Charles's cases show the importance of freely discussing the dilemma with the person with ID in order to find a solution that can be accepted by all parties. Although the decisions were difficult and Charles's wish was not granted, Charles and Sabine were both involved in discussions to resolve the dilemmas, as well as the consequences, which shows an attempt to respect their autonomy.

\section{DISCUSSION}

Respect for autonomy in the end-of-life care of people with ID, as summarised in Fig. 1, was mainly reflected in helping the person with ID familiarise with three transitions: new information on the diagnosis and prognosis, changing care needs and wishes, and important decisions that were at stake. The challenges and qualities that were found in this study are discussed below, as well as their correspondence to a relational concept of autonomy.

\section{Challenges in respecting autonomy}

Respecting autonomy implied hard work. The hurdles that caregivers and relatives needed to overcome were diverse and often related to the persons' cognitive level. It was very hard to identify information needs, elicit care needs and uncover wishes in people with severe ID. In people with milder ID, relatives and caregivers struggled to resolve dilemmas with conflicting wishes and strived to find ways to communicate without upsetting the person with ID.

As patients, people with ID have a basic right to be informed about diagnosis and treatment options. It is the foundation for informed decision-making. For our interviewees, the challenge in respecting autonomy meant making a careful balance between protecting and giving more information. Moral challenges around truthtelling have also been found in advanced dementia care (Hertogh et al. 2004) and have been extensively addressed by Tuffrey-Wijne for the care for people with ID. Tuffrey-Wijne states that breaking bad news to people with ID is a process, and that truth-telling should be facilitated so it can contribute to making people with ID better informed (Tuffrey-Wijne 2012). Some authors suggest that communication about end-of-life wishes and preferences should take place earlier in life, when people are healthier and better able to communicate, for example by using a life story, values assessment, or a preferred places-of-care plan (Watchman 2005; Foster et al. 2006; 
Bekkema, N., Veer, A.J.E. de, Hertogh, C.M.P.M., Francke, A.L. Respecting autonomy in the ench of-life care of people with intellectual disabilities: a qualitative multiple-case study. Journal of Intellectual Disability Research: 2014, 58(4), 368-380

Stein \& Kerwin 2010). We do think that early attention to wishes and preferences can contribute to a respect for autonomy if it helps people with ID to make their own choices about end-of-life care. It is, however, still essential that caregivers and relatives keep an open eye for the current needs and wishes, as needs and wishes can change at the end of life. Relatives in particular struggled to involve the person with ID in important decisions. Lack of involvement in end-of-life decision-making clearly remains an issue that may severely undermine the autonomy of people with ID (Stein 2008; Wagemans et al. 2010, 2012). Although several decision-making approaches have been described for aiding the involvement of people with ID in endof-life decisions (Beltran 1996; Friedman 1998; Kleespies 2004; Stein \& Kerwin 2010), they have been insufficiently investigated with regard to the actual participation of people with ID.

\section{Qualities in respecting autonomy}

The cases show that respecting autonomy at the end of life is about opening up and understanding the person's perspective, as attention to information needs, connecting with the person with ID and giving space to show wishes and preferences were important qualities in relatives and caregivers when helping the person with ID familiarise with transitions. The cases also show that respecting autonomy at the end of life should focus on addressing the specific needs of people with ID in their last phase of life, as acknowledging an end-of-life care need and discussing dilemmas were important qualities as well. Even though the lives of the people in the cases studied were characterised by lifelong dependence, their dependence was particularly evident and burdensome for their relatives who needed to make important decisions on behalf of a person with severe ID who lacked decision-making capacity. The Netherlands has a model of substitute decision-making for incompetent people in which representatives (usually a close relative) have the legal power to make substitute decisions (Welie et al. 2005). Emotions ran high and relatives felt overpowered by the responsibility of taking weighty decisions at the end of life. It made them wonder what they had already unconsciously filled in for the person with ID earlier in life. In most of the cases studied, many things changed rapidly for the people with ID, which underscored the importance of actively addressing the sick person's needs and may explain why respect for autonomy was mainly an issue in transitional situations. The qualities we found all stress the importance of an overall active attitude to 'attaining' autonomy. This makes respecting autonomy sound almost passive in comparison with attaining, ensuring or enhancing autonomy.

\section{Respecting autonomy: a relational concept?}

Our results indicate that a relational concept of autonomy is useful for describing respect for autonomy in end-of-life care for people with ID, but that caregivers and relatives do not always sufficiently employ the relationship to attain autonomy. Relatives and caregivers made numerous references to efforts to help the sick person with ID get through transitions by utilising their relationship. These efforts fit within a relational notion of autonomy, such as in Agich's work where autonomy has been defined as the ability to identify with changing circumstances (Agich 2003). Our results are in accordance with Agich's 'actual autonomy', as Agich explains that when people are impaired, caregivers have the responsibility to help a sick person 
Bekkema, N., Veer, A.J.E. de, Hertogh, C.M.P.M., Francke, A.L. Respecting autonomy in the ench of-life care of people with intellectual disabilities: a qualitative multiple-case study. Journal of Intellectual Disability Research: 2014, 58(4), 368-380

identify with his or her autonomy, a notion that is also supported by some other authors on end-of-life care (Proot et al. 2004; Vernooij-Dassen et al. 2005). The qualities we found to be important also show similarities to the core values of 'good care' in care ethics, such as the attentiveness, responsibility, competence and responsiveness of Joan Tronto (Tronto, 1993) and to the work of Verkerk and Maeckelberghe who wrote that respecting the autonomy of people with ID implies listening to their story, empathising with their view of the world and helping them stay close to themselves (Verkerk \& Maeckelberghe 2003). Respecting autonomy sometimes led to severe burdens, especially for relatives of people with a severe ID who had to decide for their beloved one and wished the person was able to decide for himself/herself. These wishes appear to tie in with liberal concepts of selfdetermining individuals and independence, but in view of the cases studied they are better interpreted as a deep desire for more togetherness and for enlarging the role of the person with ID in the decision-making process. However, some relatives and caregivers regarded communication and involvement simply as impossible, which may mean that at that point the autonomy of the people with ID in these cases was not fully respected. In such cases, relatives and caregivers were far less open to employing their relationship with the person with ID, and they would need more reflection and openness to regard autonomy as a product of 'joint work'.

\section{Strengths and limitations}

By using a multiperspective design, we were able to reconstruct the story of 12 deceased people with ID, incorporating the viewpoints of all people who were most closely involved, such as their relatives, social workers, nurses and physicians. This helped avoid giving too much emphasis to the viewpoint of one single person. The study was performed retrospectively, which is a limitation as the experiences of the interviewees at the actual time that end-of-life care took place remain unknown. On the other hand, a retrospective study makes interviewees' statements less susceptible to day-to-day emotions. Another limitation of our retrospective design is that the experiences of the people with ID themselves could not be studied. A more in-depth study, including participative observation and interviews with people with ID themselves, could give more insight into the qualities of caregivers and relatives that contribute to or undermine autonomy.

\section{Conclusion and implications}

Our material shows a lot of potential for respecting autonomy. If relatives and caregivers embrace autonomy as a relational construct, to be attained by an open, active and reflective attitude, and have more knowledge on communication and identifying end-of-life care needs, this could lead to greater respect for the ID persons' autonomy at the end of life. In practice this implies that ID care providers should encourage team meetings that enable caregivers to jointly discover the options for involving people with ID in communication and decision-making. This may expand the opportunities for helping an ID person become at ease with transitions at the end of life. However, fully respecting the autonomy of people with ID in their last phase in life will be an illusion if caregivers lack the basic skills to provide good end-of-life care. Care providers should therefore also invest seriously in educating their caregivers in recognising and addressing end-of-life care needs. 
Bekkema, N., Veer, A.J.E. de, Hertogh, C.M.P.M., Francke, A.L. Respecting autonomy in the ench of-life care of people with intellectual disabilities: a qualitative multiple-case study. Journal of Intellectual Disability Research: 2014, 58(4), 368-380

\section{ACKNOWLEDGEMENTS}

This research was funded by the Dutch Ministry of Health, Welfare and Sport, the Sluyterman van Loo Foundation, the RCOAK foundation and the Intellectual Disabilities Foundation.

\section{REFERENCES}

Agich G. J. (2003) Dependence and Autonomy in Old Age: An Ethical Framework for LongTerm Care. Cambridge University Press, Cambridge, UK.

Beauchamp T. L. \& Childress J. F. (2001) Principles of Biomedical Ethics. Oxford University Press, Oxford.

Beltran J. E. (1996) Shared decision making: the ethics of caring and best respect. Bioethics Forum 12, 17-25.

Claessen S. J., Francke A. L., Belarbi H. E., Pasman H. R., van der Putten M. J. \& Deliens L. (2011) A new set of quality indicators for palliative care: process and results of the development trajectory. Journal of Pain and Symptom Management 42, 169-182.

Ellison N. M. \& Rosielle D. (2008) Palliative care for adults with developmental disabilities. Journal of Palliative Medicine 11, 1262-1263.

Foster J., Harrison T., Whalley H., Pemberton C. \& Storey L. (2006) End-of-life care: making choices. Learning Disability Practice 9, 18-22.

Friedman R. I. (1998) Use of advance directives: facilitating health care decisions by adults with mental retardation and their families. Mental Retardation 36, 444-456.

Hertogh C. M. P. M., The B. A. M., Miesen B. M. L. \& Eefsting J. A. (2004) Truth telling and truthfulness in the care of patients with advanced dementia. Social Science and Medicine 59, 1685-1693.

Janicki M. P., Dalton A. J., Henderson C. M. \& Davidson P. W. (1999) Mortality and morbidity among older adults with intellectual disability: health services considerations. Disability Rehabilitation 21, 284-294.

Kleespies P. M. (2004) Life and Death Decisions: Psychological and Ethical Considerations in End-of-Life Care. American Psychological Association, Washington, DC.

McCallion P., McCarron M., Fahey-McCarthy E. \& Connaire K. (2012) Meeting the end of life needs of older adults with intellectual disabilities. In: Contemporary and Innovative Practice in Palliative Care (eds E. Chang \& A. Johnson ), pp. 255-270. Intech, Rijeka, Croatia.

Maeckelberghe E. L. M. (2003) Tegenstrijdige belangen in de zorg: een zorgethische benadering. Lezing in het kader van de Studiedag te Nieuw Wehl 'Tegenstrijdige belangen in de zorg' (Conflicting interests in health care: a care-ethics approach), commissie ethiek van de Passerel, Zozijn en Fatima (verstandelijk gehandicaptenzorg).

Proot I. M., Abu-Saad H. H., ter Meulen R. H., Goldsteen M., Spreeuwenberg C. \& Widdershoven G. A. (2004) The needs of terminally ill patients at home: directing one's life, health and things related to beloved others. Palliative Medicine 18, 53-61.

Ryan K. \& McQuillan R. (2006) Ethical decision making. In: Palliative Care for People with Learning Disabilities (ed. S. Read), pp. 75-93. Quay Books, London.

Stein G. L. (2008) Providing palliative care to people with intellectual disabilities: services, staff knowledge, and challenges. Journal of Palliative Medicine 11, 1241-1248.

Stein G. L. \& Kerwin J. (2010) Disability perspectives on health care planning and decisionmaking. Journal of Palliative Medicine 13, 1059-1064.

Tronto J. (1993) Moral Boundaries: A Political Argument for an Ethic of Care. Routledge, New York.

Tuffrey-Wijne I. (2012) A new model for breaking bad news to people with intellectual disabilities. Palliative Medicine 27, 5-12.

Tuffrey-Wijne I. \& McEnhill L. (2008) Communication difficulties and intellectual disability in end-of-life care. International Journal of Palliative Nursing 14, 189-194.

Tuffrey-Wijne I., Hollins S. \& Curfs L. (2005) Supporting patients who have intellectual disabilities: a survey investigating staff training needs. International Journal of Palliative Nursing 11, 182-188. 
Bekkema, N., Veer, A.J.E. de, Hertogh, C.M.P.M., Francke, A.L. Respecting autonomy in the ench of-life care of people with intellectual disabilities: a qualitative multiple-case study. Journal of Intellectual Disability Research: 2014, 58(4), 368-380

Tuffrey-Wijne I., Bernal J., Jones A., Butler G. \& Hollins S. (2006) People with intellectual disabilities and their need for cancer information. European Journal of Oncology Nursing 10, 106-116.

Tuffrey-Wijne I., Bernal J., Hubert J., Butler G. \& Hollins S. (2009) People with learning disabilities who have cancer: an ethnographic study. British Journal of General Practice 59, 503-550.

Tuffrey-Wijne I., Bernal J. \& Hollins S. (2010) Disclosure and understanding of cancer diagnosis and prognosis for people with intellectual disabilities: findings from an ethnographic study. European Journal of Oncology Nursing 14, 224-230.

Van Hooren R. H., Widdershoven G. A. M., Borne H. W. \& Curfs L. M. G. (2002) Autonomy and intellectual disability: the case of prevention of obesity in Prader-Willi syndrome. Journal of Intellectual Disability Research 46, 560-568.

Verkerk M. A. (1999) A care perspective on coercion and autonomy. Bioethics 13, 358-368.

Verkerk M. A. (2001) The care perspective and autonomy. Medicine Health Care and Philosophy 4, 289-294.

Verkerk M. A. \& Maeckelberghe E. L. M. (2003) Zelf vragen? het concept van autonomie vanuit het perspectief van een relationele ethiek (Ask yourself? The concept of autonomy from the perspective of relational ethics). Pedagogisch Tijdschrift 28, 141-158.

Vernooij-Dassen M. J., Osse B. H., Schadé E. \& Grol R. P. (2005) Patient autonomy problems in palliative care: systematic development and evaluation of a questionnaire. Journal of Pain and Symptom Management 30, 264-270.

Wagemans A., Lantman-de-Valk H., Tuffrey-Wijne I., Widdershoven G. \& Curfs L. (2010) End-of-life decisions: an important theme in the care for people with intellectual disabilities. Journal of Intellectual Disability Research 54, 516-524.

Wagemans A., van Schrojenstein Lantman-de Valk H., Proot I., Metsemakers J., TuffreyWijne I. \& Curfs L. (2012) The factors affecting end-of-life decision-making by physicians of patients with intellectual disabilities in the Netherlands: a qualitative study. Journal of Intellectual Disability Research doi: 10.1111/j.1365-2788.2012.01550.x.

Watchman K. (2005) Practitioner-raised issues and end-of-life care for adults with Down syndrome and dementia. Journal of Policy and Practice in Intellectual Disabilities 2, 156162.

Welie S. P., Dute J., Nys H. \& Van Wijmen F. C. (2005) Patient incompetence and substitute decision-making: an analysis of the role of the health care professional in Dutch law. Journal of Public Health Policy 73, 21-40.

Winzelberg G. S., Hanson L. C. \& Tulsky J. A. (2005) Beyond autonomy: diversifying end-oflife decision-making approaches to serve patients and families. Journal of the American Geriatrics Society 53, 1046-1050.

Wullink M., Widdershoven G., van Schrojenstein Lantman-de Valk H., Metsemakers J. \& Dinant G. J. (2009) Autonomy in relation to health among people with intellectual disability: a literature review. Journal of Intellectual Disability Research 53, 816-826. 
Bekkema, N., Veer, A.J.E. de, Hertogh, C.M.P.M., Francke, A.L. Respecting autonomy in the ench of-life care of people with intellectual disabilities: a qualitative multiple-case study. Journal of Intellectual Disability Research: 2014, 58(4), 368-380

\section{TABLES AND FIGURE}

Table I General overview of the cases: the deceased people and the interviewees

\begin{tabular}{|c|c|c|}
\hline & Relatives & $\begin{array}{l}\text { Professional or volunteer } \\
\text { caregivers }\end{array}$ \\
\hline Case I: female, died from dementia, moderate intellectual disability (ID) & I friend & $\begin{array}{l}\text { I nurse } \\
\text { I ID physician } \\
\text { I psychologist }\end{array}$ \\
\hline Case 2: female, died from metabolic disease, severe/profound ID & I mother & $\begin{array}{l}2 \text { social workers } \\
\text { I home-nurse } \\
\text { I general practitioner (GP) }\end{array}$ \\
\hline Case 3: female, died from kidney and heart failure, mild ID & $\begin{array}{l}\text { I sister } \\
\text { I brother-in-law }\end{array}$ & $\begin{array}{l}\text { I social worker } \\
\text { I GP }\end{array}$ \\
\hline Case 4: male, died from cancer, mild ID & $\begin{array}{l}\text { I sister } \\
\text { I brother-in-law }\end{array}$ & $\begin{array}{l}\text { I social worker } \\
\text { I nurse specialised in palliative care } \\
\text { I GP } \\
\text { I volunteer }\end{array}$ \\
\hline Case 5: female, died from cancer, mild ID & & $\begin{array}{l}\text { I specialised social worker } \\
\text { I nurse }\end{array}$ \\
\hline Case 6: male, died from cancer, severe/profound ID & I sister & $\begin{array}{l}\text { I social worker } \\
\text { I ID physician }\end{array}$ \\
\hline Case 7: male, died from metabolic disease, severe/profound ID & I mother & $\begin{array}{l}\text { I social worker } \\
\text { I nurse } \\
\text { I ID physician }\end{array}$ \\
\hline Case 8: male, died from cancer, mild/moderate ID & I sister & $\begin{array}{l}2 \text { social workers } \\
\text { I ID physician }\end{array}$ \\
\hline Case 9: male, died from cancer, mild ID & 2 sisters & $\begin{array}{l}\text { I social worker } \\
\text { I hospice co-ordinator } \\
\text { I volunteer }\end{array}$ \\
\hline Case I0: female, died from dementia, moderate ID & I brother & $\begin{array}{l}\text { I nurse } \\
\text { I ID physician }\end{array}$ \\
\hline Case II: male, died from old age frailty, severe/profound ID & I brother & $\begin{array}{l}\text { I social worker } \\
\text { I end-of-life care consultant }\end{array}$ \\
\hline Case I2: female, died from cancer, moderate ID & I sister & $\begin{array}{l}2 \text { social workers } \\
\text { I ID physician }\end{array}$ \\
\hline Total & 16 & 31 \\
\hline
\end{tabular}


Bekkema, N., Veer, A.J.E. de, Hertogh, C.M.P.M., Francke, A.L. Respecting autonomy in the ench of-life care of people with intellectual disabilities: a qualitative multiple-case study. Journal of Intellectual Disability Research: 2014, 58(4), 368-380

Figure 1 Respecting autonomy: challenges and important qualities. ID, intellectual disability.

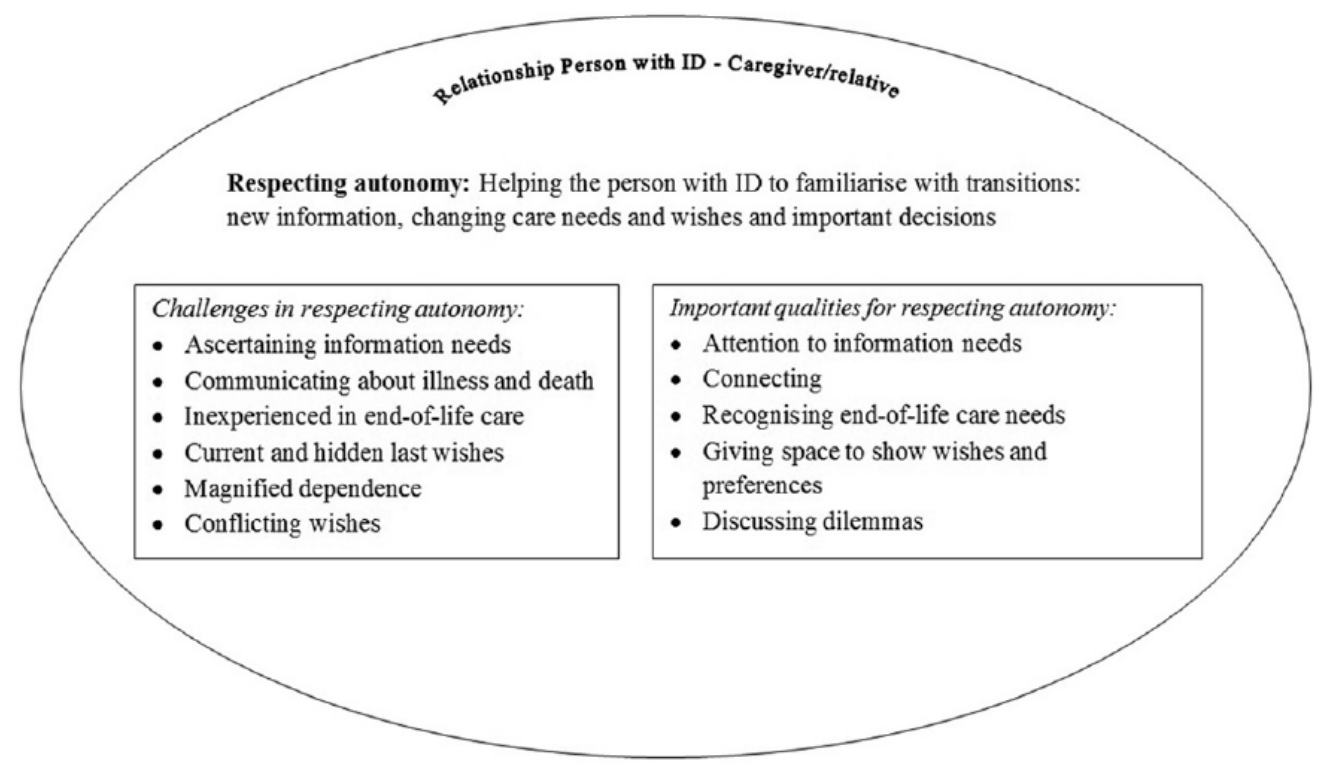

Table 2 Cases illustrating the role of autonomy in end-of-life care

The names used in the case descriptions are not the subjects' real names.

Joe was a man aged 40 with a severe intellectual disability (ID) and lung cancer. Joe lived in a small-scale residential home on the premises of an ID care provider.

Cassandra was a woman aged 49 with a moderate ID and colorectal cancer. Before her illness, Cassandra lived in her own apartment on the premises of an ID care provider. Cassandra worked on a farm, together with other people with ID. When she became ill, she moved to an intensive care department.

Sabine was a woman with a mild ID and behavioural problems; she was regularly aggressive. When Sabine was 7I, she got stomach cancer. Sabine had her own apartment in a centre for supervised living. Sabine had daily supervision for several hours.

Charles was a man with a mild ID and serious physical limitations. He had deformities and hemiplegia. Charles used to communicate with a speech computer. When he was 69 he got cancer. Before his illness he lived independently in an apartment with daily supervision. 